\title{
Primary palliative care for surgeons: a narrative review and synthesis of core competencies
}

\author{
Buddy Marterre ${ }^{1}$, Kimberly Kopecky ${ }^{2}$, Pringl Miller ${ }^{3}$ \\ ${ }^{1}$ Departments of General Surgery and Internal Medicine, Wake Forest Baptist Health, Winston-Salem, NC, USA; ${ }^{2}$ Department of Surgery, Stanford \\ Hospitals and Clinics, Stanford, CA, USA; ${ }^{3}$ Founder \& Executive Director, Physician Just Equity, San Francisco, CA, USA \\ Contributions: (I) Conception and design: All authors; (II) Administrative support: None; (III) Provision of study materials or patients: None; (IV) \\ Collection and assembly of data: None; (V) Data analysis and interpretation: None; (VI) Manuscript writing: All authors; (VII) Final approval of \\ manuscript: All authors. \\ Correspondence to: Dr. Buddy Marterre, MD, MDiv. Departments of General Surgery and Internal Medicine, Wake Forest Baptist Health, Winston- \\ Salem, NC, USA. Email: b.marterre@wakehealth.edu.
}

\begin{abstract}
The practice of palliative medicine has grown substantially over the last two decades and the data demonstrates that seriously ill and injured surgical patients as well as their loved one's benefit from the integration of palliative care into standard surgical management. This narrative review highlights the patient and family benefit of primary surgical palliative care (PSPC) for seriously ill or injured surgical patients and the need for primary palliative care (PPC) skill acquisition by surgeons. The review encourages surgeons to identify all aspects of suffering as a critical component of the care needs of surgical patients and families and to consider integrating mitigation strategies during surgical care. Identification of suffering has not been traditionally taught in surgical training or reinforced in surgical practice, therefore current surgical educational opportunities should incorporate such instruction to assist surgeons in training and in practice to acknowledge and treat suffering to improve and expand the quality and value of surgical care offered to seriously ill or injured surgical patients. Additionally, a patient-centered approach to surgical care necessitates engaging advanced communication skills to successfully ascertain a patient's and/or their surrogate decision maker's, substituted goals and values in the provision of surgical care to ensure that all the care delivered is aligned with each patient's preferences. A preliminary synthesis of core competencies to achieve these SPC objectives is presented.
\end{abstract}

Keywords: Primary palliative care (PPC); surgical palliative care (SPC); core competencies; communication skills; symptom management

Submitted Feb 10, 2021. Accepted for publication Aug 03, 2021.

doi: 10.21037/apm-21-369

View this article at: https://dx.doi.org/10.21037/apm-21-369

"Surgical palliative care is the treatment of suffering and the promotion of quality of life for seriously ill patients under surgical care."-Geoffrey P. Dunn, MD, FACS.

\section{Introduction}

The history of surgery and the moral imperative to palliate pain and suffering are intimately intertwined (1). The practice of surgical palliative care (SPC) is defined by the treatment of suffering and the promotion of quality of life (QOL) for seriously ill patients and those with lifethreatening conditions under surgical care $(2,3)$ regardless of the stage of their disease or parallel employment of lifeprolonging therapies. The primary goal of a palliative care (PC) clinician is to recommend treatment modalities that reduce suffering and help patients and their loved ones achieve their best QOL in the context of serious illness. Existing data suggests that the provision of PC concurrent with disease-directed therapy is beneficial for patients and their loved ones (4). Palliative care should be differentiated 
from hospice as care that is delivered to all patients with a serious illness regardless of life expectancy. Thusly, palliative care should function as "supportive concurrent care" for all seriously ill and injured surgical patients with palliative care needs (5). The provision of SPC involves empathic surgeonpatient partnering that embraces patient values, autonomy, and dignity, and optimizes QOL by anticipating, preventing, and treating suffering throughout the continuum of illness by addressing physical, intellectual, emotional, social, and spiritual needs (5). Ideally, this holistic approach to surgical care is provided in parallel with value-concordant diseasedirected therapies (6) which include surgery, procedures, or other medical treatments.

Surgical care, as currently practiced, often fails to satisfy the palliative needs of seriously ill or injured surgical patients (7), as surgeons often erroneously view surgical intervention and palliation as mutually exclusive (8). Gaps in whole person care have been identified and can be addressed by concurrent primary and/or specialty palliative care as each patient's needs dictate (4). In order for surgeons to integrate palliative care into their practice patterns, a greater understanding of the added benefit is required and additional training must be obtained. Surgeons should consider pivoting from an aggressive "do everything" ethos and "fix-it" mentality to a more patient-centered mindset or framework, which places patient values, goals and QOL at the center of clinical decision-making. Bateni et al. published that surgeons offer more aggressive therapies for patients suffering with advanced cancer as compared to their medical colleagues with more palliative care training (9). The lack of palliative care training during surgical career development often prevents optimal engagement with patients about their goals, values, and alternatives to invasive surgical intervention leading to recommendations for aggressive non-beneficial end-of-life (EOL) care.

Surgical ethos demands that surgeons never "give up", yet this deeply-ingrained philosophy fosters an unrealistic and self-defeating attitude toward progression of disease as "failure," as if all death was preventable (10-12). Aslakson and coauthors have emphasized that critical care clinicians often have misconceptions that palliative care consultation will lead to early patient death and is representative of "giving up." They describe this perception as a significant barrier to both providing palliative care and producing high quality data relevant to the effectiveness of palliative care in the critical care environment (13). What, then, is primary surgical palliative care (PSPC)?

The Institute of Medicine defines primary palliative care
(PPC) as "palliative care that is delivered by health care professionals who are not palliative care specialists" (14). We define PSPC as the provision of core palliative care (PC) principles by practitioners who work with surgical patients and their families, whether as the surgeon, trainee, or any other member of the surgical treatment team. The core principles of PSPC describes the minimal skill set that all surgeons should bring to their patient encounters. These minimal skills include core practice elements such as aligning treatment with patient goals and values by engaging in discussions about suffering, prognosis, goals of care, and EOL preferences as well as management of symptoms (15).

Surgeons have a rich history of providing surgical palliation since at least the $19^{\text {th }}$ century (16) when Theodore Billroth performed a partial gastrectomy for a patient with pyloric cancer who was presumably suffering from gastric outlet obstruction (15). More recently, patient opinions about the integration of PC into routine surgical management have been uniformly positive (17). Therefore, an opportunity exists to provide patient-centered evidencebased concurrent palliative care when treating seriously and injured surgical patients. This approach to surgical practice enhances patient and family satisfaction and may increase survival (18). Multiple studies have reinforced the patient-centered benefits of concurrent palliative care, which has informed the 21 st-century surgeon's focus beyond mastering anatomy, pathophysiology, and an everincreasingly sophisticated array of techniques for procedural and operative interventions. Furthermore, many surgeons prioritize procedural success over knowing and honoring a patient's core values. Hall et al. remind surgeons that the ultimate success of surgery is determined by how well surgical care fosters a patient's flourishing (17).

We present the following article in accordance with the Narrative Review reporting checklist (available at https:// apm.amegroups.com/article/view/10.21037/apm-21-369/rc).

\section{An unmet need}

There are significant barriers to meeting the needs of hospitalized surgical patients suffering from serious illnesses. First, there is a dearth of palliative care education available to surgeons and surgical trainees $(1,19-21)$. Second, there is a shortage of PC specialists. Finally, palliative care consults often come as very late referrals during a surgical patient's clinical course (22-24). In a 2012 seminal publication, Quill and Abernathy (25) noted that "there are nowhere near enough 
palliative care specialists to provide all palliative care services for every very ill patient... (and the) increasing demand for palliative care will soon outstrip the supply of providers". As of 2019, there were 7,408 active physicians who were certified in hospice and palliative medicine; including eighty PC subspecialists also board certified in surgery (1.1\% of the total) (23). With fewer than 250 fellowship-trained PC graduates each year, there is a projected PC specialist shortage of greater than 16,000 by 2030 (26). It was in this context that the National Academy of Medicine's landmark 2015 report, "Dying in America: Improving Quality and Honoring Individual Preferences Near the End of Life", specifically recommended that PC principles be incorporated into health care education so that every clinician, regardless of specialty, would be skilled in providing PPC (27). With this shortage in mind, along with the known benefits of SPC, the need for PSPC education and provision cannot be overstated.

A 2017 survey of physicians who treat advanced cancer patients found that surgeons received a median of ten hours of PC training compared with medical oncologists who had a median of 30 hours, and medical intensivists who had a median of 50 hours. Astonishingly, 25\% of cancer surgeon respondents reported no PC training at all (9). A national survey of surgical oncology fellows found that more than one-half of them directly avoided telling patients that they were dying (19). In another survey, the percentages of neurosurgery residents who reported no explicit teaching on the risks and benefits of invasive mechanical ventilation and formulating prognoses in neurocritical care were $69 \%$ and $60 \%$ respectively; one half reported that they "would benefit from more communication training" (28).

Surgical PC experts have touted collaboration with nonsurgical PC experts for decades, both from outside and inside the ICU $(8,29,30)$. Most surgeons, however, fail to consult PC experts, such that PC collaboration on surgical patients remains underutilized (31-33) despite the proven benefits of PC for many surgical patient populations $(34,35)$. The most studied surgical patients with unmet PC needs have advanced malignancies, need emergency general surgery, or suffer from traumatic injuries. Gani et al. found that inpatient PC services were used $8.5 \%$ of the time during an initial admission for cancer. They found that patients admitted with gastrointestinal or thoracic malignancies undergoing surgery were $79 \%$ less likely to receive PC consultation than patients who did not undergo surgery during their inpatient admission (36). Likewise, Evans and coauthors found that PC consultation was requested in only $37 \%$ of cases where critically ill general surgery patients died during hospital admission (37). Aslakson et al. reviewed 37 publications that addressed the evidence base of thirty PC interventions in the ICU. These investigators concluded that "proactive palliative care in the ICU... decrease bospital and ICU LOS, do not affect (patient/family) satisfaction, and either decrease or do not affect mortality" (13). Maerz et al. analyzed the American Association for the Surgery of Trauma (AAST) Futility Survey, and reported that $84 \%$ of respondents answered "no" when asked if PC teams round with the trauma ICU team; the most common reasons for PC consultation were family request, anticipation of care goal disagreement, and if the patient was considered to have a significant chance of dying (38). Liu and colleagues found that PC utilization in patients suffering from ruptured abdominal aortic aneurysms was associated with a shorter hospital length of stay (4.6 vs. 9.7 days), lower charges ( $\$ 96 \mathrm{k} v$ s. $\$ 178 \mathrm{k}$ ), and a decreased rate of prolonged invasive mechanical ventilation (13\% vs. $17 \%$ ), even though PC integration was only utilized in $14 \%$ of cases (39). Lilley et al. systematically reviewed the literature on PC interventions in surgical patients through 2014. Preoperative decision-making interventions were associated with decreased mortality in 4 studies; 3 reported improved communication; 4 improved symptom management; and 7 decreased healthcare resource utilization and cost (40).

The economic and clinical value of PC is increasingly becoming recognized within the healthcare industry, as emerging data and societal benefits are understood, yet significant barriers remain. The reasons for these barriers are complex and have been extensively documented in the literature (41). Dr. Cocanour expressed the need to incorporate PC principles into trauma care in her 2015 Presidential Address to the Western Trauma Association (42). In her address, she exhorted making a change to an outdated mindset toward surgical priorities by saying: "We (wrongly) measure success not by QOL but by morbidity and mortality. Death is considered a failure, and we associate palliative care with giving up, (but) palliative care is not only for those at the end of life." (42).

As the US population progressively ages, patients' impending PC needs will continue to exceed the number of PC specialists available, thus mandating more surgeonspecific application of PPC skills. The prevalence of PC needs for a given surgical patient varies according to comorbidities, prognosis, acuity, physical and cognitive frailty, and the risks of any proposed procedures (43-52). In a study of the surgical patient population being treated for advanced pancreatic cancer (where survival is measured 
in months), one third of the inpatients had no documented discussions about their goals of care or preferred code status (53). Older adults who present with emergency abdominal surgical conditions account for over a million inpatient admissions in the United States per year (54). Multiple research studies in this patient population have demonstrated that baseline preoperative comorbidities and frailty dramatically increase the likelihood of both inhospital and 1-year mortality, as well as increased rates of function-limiting morbidity and discharges to post-acute care facilities (7,54-56).

Surgical palliative care is value-centered surgical care $(57,58)$. Most patients place value on good pain and symptom management, functional independence, meaningful interactions with family, their spirituality, avoiding burdening their loved ones, minimizing nursing facility stays, and preventing unnecessary prolongation of the dying process (59-63). In 2015, Scheunemann and colleagues found that deliberations on patient values and preferences were recorded in the minority of the 249 surrogate decisionmaking conferences studied, and within this minority, patient values were only discussed superficially (64). Less than $10 \%$ of the family conferences contained robust discussion elements of prolonged physical, cognitive, or emotional impairment; and less than $5 \%$ documented the patient's spirituality, despite spirituality being a highly prevalent concern in seriously ill patients $(65,66)$. Less than $10 \%$ of conferences culminated in clinicians offering valuecentered treatment recommendations, despite this being a critical component of shared decision-making (SDM) (67). Beyond facilitating the patient's autonomy, clearly relaying substituted judgement principles $(68,69)$ in family meetings has the potential to relieve family members of guilt, anxiety, depression, and post-traumatic stress symptoms $(70,71)$, as well as mitigate complex grief in survivors $(72,73)$. Unfortunately, this was proffered in only $13.5 \%$ of the family meetings that Scheunemann and her collaborators analyzed (64). These studies reveal the need for PPC interventions and documentation in the perioperative critical care setting.

Every healthcare provider should be able to perform spiritual screening $(14,74)$ given how important spirituality, hope and meaning-making is to patients with serious illness $(65,66)$. Spirituality is a topic that routinely makes surgeons uncomfortable (75-77), and this area is an unmet need from surgical patients' perspectives. Spiritual screening provides an opportunity for surgeons to take a first step toward deeper inquiry into the beliefs, practices, and deep sources of meaning of their patients $(66,77)$. Studies have found that single-question screens for religious/spiritual distress are inadequate, and that combining two questions-one of meaning/joy and a second of self-described spiritual struggle or suffering (such as feeling disconnected from God or other deep sources of meaning/purpose)—is superior (78).

Patient preferences to maintain functional independence, preserve meaningful interactions with loved ones, and avoid a prolonged dying process are also critical to patientcentered surgical care. Rubin et al. recently reported that $87 \%$ of patients who were 60 years and older suffering from serious oncologic, cardiac, and pulmonary illnesses said that they would trade a full year of life to avoid a 3-week intensive care unit (ICU) stay that led to death on life support (79). The implications for ICU care are enormous, as postoperative and trauma critical care environments frequently offer patients the antithesis of value-congruent "care". Rapid advances in technology have impacted surgeons, patients, and families alike who all struggle with clinical ambiguity and uncertainty $(80,81)$. Clinical ethicist Elizabeth Sonntag writes that this leaves clinicians who recommend high-tech life support technologies "unprepared to face the ethical and emotional dimensions of caring for patients" (81). Indeed, many surgeons continue to offer evermore complex "supportive" technical treatment options to families in the ICU, which can promote a seeminglyunstoppable locomotive of escalating value-incongruent non-beneficial treatments (82). When family members express a desire to transition care goals toward comfort, surgeons may express reluctance to withdraw life-sustaining medical treatments (LSMT) $(41,83)$, particularly if they feel responsible for committing an error (84-87).

Most of the literature regarding systematic triggers to increase the utilization of expert PC consultation for surgical patients has come from studies in the ICU $(88,89)$. In a 2006 report, Mosenthal and Murphy found that when a structured interdisciplinary model for PC was integrated into standard ICU care, the rates of mortality, do not resuscitate (DNR) orders, and withdrawal of LSMT were unchanged; however, placement of DNR orders and withdrawal of LSMT occurred earlier in the clinical course, therefore decreasing the ICU length of stay for those who died (90). In a separate study, Finkelstein et al. reported hospital death plus hospice discharge rates to be $81 \%$ for patients requiring repeat surgical ICU admission, $75 \%$ in patients with metastatic or advanced cancer, $55 \%$ for patients with two or more major organ system failures, and $51 \%$ for patients who had surgical ICU stays longer than 
10 days (91). Wilson et al. described 81 vascular surgery patients who transitioned care goals from disease-directed therapies to comfort-focused care (92). In this study, conversion to comfort focused care was greater than four times as likely for patients with a surgical ICU admission greater than 5 days, was greater than nine times as likely for patients who had spent more than 5 days on mechanical ventilation, was greater than fourteen times as likely for new renal failure requiring renal replacement therapy (RRT) and was nearly 24 times as likely for patients with new respiratory failure requiring a tracheostomy. Thirtyone of the 81 patients studied chose comfort-focused care despite being offered medical and/or surgical treatment; the median time from PC consultation to death was only 10 hours. Finally, Nabozny et al. compared the trajectories and prognosis of 4,944 older Medicare beneficiaries who had more than 96 hours of mechanical ventilation after high-risk surgery with 112,973 patients who did not (93). Thirty-day mortality for patients receiving prolonged mechanical ventilation was $32 \%$ as compared to $4.8 \%$ for no prolonged mechanical ventilation and only $10 \%$ of prolonged ventilation patients who were still alive on postoperative day 30 were discharged home, compared to $71 \%$ of the comparison patients. Taken together, these studies demonstrate the potential for perioperative complications to significantly affect both mortality and QOL for patients undergoing surgical intervention. Furthermore, they illuminate barriers to PC consults for the sickest surgical patients, which may be due to surgeons' interventionorientation $(94,95)$ and their focus on outcomes rather than patient values (96). Multiple studies have correlated the lack of palliative care training on the provision of more aggressive non-beneficial operative and perioperative interventions $(9,56)$.

Bradley et al., in a 2010 study, showed that initiation of a trigger-based consultation system (relying on ten clinical triggers to suggest but not mandate a PC consultation) had no effect on increasing $\mathrm{PC}$ consultations given that triggers were rare both pre-intervention and post-intervention; PC consultation was infrequent in both groups (97). The authors conclude: "Our data confirm that the triggers successfully identify those patients who are at a relatively high risk for a poor outcome (>50\% mortality), but the greater majority of patients in the SICU, who may also have physical, emotional, or spiritual palliative needs, will not benefit from...the use of these triggers alone." (97). This research team laid out an alternative strategy for PC consultation, including a daily assessment of pain and symptom control, prognostication, psychosocial and spiritual support, and advanced care planning needs (97).

Studies are underway to evaluate routine inclusion of specialist PC for cancer patients undergoing non-palliative oncologic surgery (98). Prior research within the Veterans Affairs (VA) medical system has shown that the survivors of high-risk surgical procedures who died and received an inpatient PC consultation were more likely to rate their loved ones' overall care, EOL communication and support as excellent when compared to families of decedents who did not receive PC (99). A corollary study within the VA system demonstrated that surgical patients were less likely to receive a PC consult than medical patients, despite the fact that $22 \%$ of the patients had at least one major surgical procedure in their final year of life (100). A study of the fee-for-service Medicare patient population demonstrated that over 31\% of patients undergo an inpatient surgical procedure during the year before death, $18 \%$ in the last month of life, and $8 \%$ in the last week of life (101). These studies suggest that at a minimum, surgical providers need to hone their frailtyidentification and prognostication skills, as well as discern the need for expert palliative care consultation.

\section{Professional guidelines}

The National Academy of Science Engineering and Medicine 2020 Building the Workforce We Need to Care for People with Serious Illness Workshop emphasized preparing all health professionals to care for people with serious illness (24). A systematic literature review revealed broad medical research support for the National Consensus Project Clinical Practice Guidelines for Quality Palliative Care (14) in the following domains of care, all of which pertain to SPC: physical, psychological, social, spiritual and ethical care of patients nearing the EOL (74). There are several surgical society statements on the practical and educational inclusion of PC principles for surgical providers. The American College of Surgeons (ACS) has two complementary statements on the principles of PC for surgical providers. The first was released in 2005 after development by the Task Force on Surgical Palliative Care and the Committee on Ethics. This Statement of Principles of Palliative Care describes practical steps to extend PC principles to patients receiving surgical care. These include but are not limited to respecting the dignity of patients and their caregivers, identifying the primary goals of care from the patient's perspective, addressing how the surgeon's care can achieve the patient's objectives, communicating effectively and empathically, alleviating distressing 
symptoms, assessing and offering access to services for psychological, social and spiritual issues, recognizing the physician's responsibility to discourage treatments that are unlikely to achieve the patient's goals, and encouraging patients and families to consider hospice care when the prognosis for survival is less than 6 months (102).

In 2017, the ACS Committee on Trauma released its Palliative Care Best Practices Guidelines (103). This 52-page document holds that "optimal care requires trauma physicians...to have basic competencies in PPC, pain and symptom management, and end-of-life care." (103). Best practice PC should be delivered in parallel with life-sustaining trauma care and core palliative care in trauma should be provided by trauma teams. This trauma document outlines essential components of PC, including skills for breaking bad news and conducting goals of care conversations, performing a PC screening assessment and deploying a "trauma palliative care bundle" within the first 72 hours of trauma admission, as well as practical guidance for the withdrawal of LSMTs when appropriate.

The Eastern Association for the Surgery of Trauma (EAST) recently published an evidence-based review of trauma center care and palliative care processes for geriatric trauma patients. This review concluded that early PC consultation was associated with improved secondary outcomes and that more research continues to be needed (104).

The National Comprehensive Cancer Network (NCCN) also offers guidelines for surgical and medical oncology providers to integrate PC into routine anti-cancer care for all patients with malignancies throughout the care continuum to anticipate, prevent and reduce suffering and to improve QOL (105). The American Society of Clinical Oncology (ASCO) 2017 guidelines recommend dedicated palliative care integration concurrent with "active treatment" early in the course when a patient is diagnosed with advanced cancer (106).

For surgical trainees in the United States, the Accreditation Council for Graduate Medical Education (ACGME) has outlined Surgical Milestones as a framework for the assessment and tracking of surgeon-in-training competency. The 2019 revision of these milestone guidelines includes documentation and assessment of trainee ability to understand and apply ethical principles, coordinate multidisciplinary care, incorporate family and patient-centered communication strategies in family meetings, utilize SDM, develop plans to manage complex postoperative conditions, discuss EOL care, deliver complex and difficult information, manage conflict, facilitate crucial conversations with patients and other healthcare providers, develop self-awareness habits, build a reflective practice and a commitment to personal growth (107).

The Surgical Council on Resident Education SCORE ${ }^{\circledR}$ Curriculum Outline for General Surgery comprehensively lists all the topics to be covered in a 5-year U.S. general surgery residency training program $(108,109)$. In addition to reviewing anatomy, pathophysiology, and operations/ procedures within the context of 27 organ system-based categories, there are sections addressing geriatric surgery and EOL care, clinical ethical issues in surgery, and interpersonal communication. Palliative care is listed as a subcategory of EOL issues; this categorization warrants revision to clarify the application of palliative care for all seriously ill patients, not just those at the EOL, and to make the distinction that palliative care-though beneficial at the EOL-is not synonymous with hospice.

The ACS published "Surgical Palliative Care: A Resident's Guide" in 2009. It provides an interactive format, teaches (or reviews) pain and symptom management, artificial nutrition and hydration, palliative surgery, crosscultural encounters, communication skills such as delivering bad news, eliciting goals of care, conducting family conferences, discussing code status, spiritual issues, and hope maintenance, as well as self-care, burnout recognition and the prevention and mitigation thereof (110).

\section{PSPC core competencies}

In a presentation at the 2003 ACS Clinical Congress, one of the founders of surgical palliative care, Dr. Bob Milch, encouraged PSPC providers to gain proficiency in what he called the "soft underbelly" of PC, which encompasses "subjects that surgeons are not always comfortable with: issues of spirituality, cross-cultural issues, and selfawareness" (75). Dr. Geoffrey P. Dunn published core competencies of surgical palliative care in 2009 (111) and applied six broad categories to these proficiencies: patient care, medical knowledge, practice-based learning and improvement, interpersonal and communication skills, professionalism, and systems-based practice. His proposed core competencies included pain and symptom management, ethical and empathic care that is patientfocused, competent and compassionate communication that includes the delivery of bad news and poor prognoses, advance directives, discovery of spirituality, reframing hope, QOL and prognostication, appropriate delivery of palliative procedures, EOL care, including transitioning from curative 
to palliative care goals and withdrawal or withholding of LSMTs as well as introspection and self-monitoring for practice improvement (111).

A 2017 systematic literature review outlined the role of surgeons in the United States in the provision of PPC. The review found that surgeons understand the benefits of PC, but are limited by experience and knowledge preventing their integration of PC into surgical decision-making and the care of their surgical patients (112). The number of training programs with formal education in PSPC skills remains limited. Prior to instituting a pilot curriculum in SPC, $94 \%$ of residents in one program claimed they had "discussed palliative care with a patient or patient's family" in the past, even though $43 \%$ of them felt uncomfortable "speaking to patients and patient's families about end-oflife issues" (113). Bradley and Brasel identified four areas of surgical practice where interpersonal communication skills are important: during preoperative decision-making, when presenting a dismal prognosis, when discussing surgical errors, and when discussing death (114). Effective this academic year (2020 to 2021), Dr. Brasel has incorporated a one-month rotation for all surgical interns at Oregon Health Sciences University (OHSU) to rotate with Dr. Timothy Siegel-a dually board-certified general surgeon and hospice and palliative medicine specialist.

Lee et al. identified 24 indicators that measure palliative processes of care across surgical episodes, which were agreed upon by an interdisciplinary expert advisory panel that included 5 surgeons, 3 hospice and palliative medicine physicians, 1 geriatrician, 1 anesthesiologist, 1 patient advocate and 1 geriatric nurse (115). The process quality indicators were developed to cover areas that were unique to surgery and are not presently addressed by PC indicators for other specialties. The process competency bar was set to identify the minimum level of PPC that all patients should receive in the absence of high-quality evidence. Most of these authors' indicators covered communication, and included documentation of prognosis, goals of surgery, patient values, likely discharge locations, functional disability, psychosocial symptom assessments, the preexistence or completion of Advance Directives and POLST forms, code status orders, surgical palliation plans, sentinel critical care events, postoperative pain and other symptom assessment and management plans, and EOL care (115).

Many publications have outlined implementation strategies for teaching surgeons and surgical trainees basic palliative care principles and skill sets. Despite these efforts and professional organization guidelines, no comprehensive set of PSPC competencies have been established. Education in Palliative and End of Life Care (EPEC) Surgery is an adaptation of the EPEC core curriculum modules adapted for surgeons and surgical trainees. There are four modules that will be available: The Surgeon-Patient Relationship, The Informed Consent Process, Breaking Bad News, and The Goals of Care Discussion (116). Using the need declarations, professional guidelines, and expert SPC panel suggestions and principles, the authors of this review have synthesized and propose a preliminary set of primary SPC competencies, which we have separated into six broad categories: (I) pain and symptom management, (II) ethics and practice of SDM, (III) communication skills, (IV) prognostication and surgical planning, (V) end-of-life care, and (VI) personal and professional growth and integration. Each competency category encompasses multiple proficiencies, which are listed using educational goal or learning objective language in Table 1. The Education Committee of the newly formed Surgical Palliative Care Society (www.SPCSociety.org) plans to examine and further refine this list of core PSPC competencies in the near future.

\section{Pain and symptom management}

The management of physical pain and other sources of suffering, such as nausea, constipation, dyspnea, agitation associated with delirium, psychological, social, and spiritual pain $(66,77)$, are key to the surgeon's initial evaluation and management of any patient facing serious illness $(115,117)$. Surgeons are more likely to engage expert PC services for assistance with EOL care than they are for symptom management (58), and yet, perhaps due to the influence of the opioid epidemic (118), medical students' witnessing patients' experience suggests that surgical patients' perioperative pain is poorly controlled, with "disturbingly graphic" descriptions that "expose suffering ranging from generalized discomfort to anguish and excruciating pain" (119). Consideration should be given to level of care (outpatient versus inpatient), route of potential medication administration (oral, intravenous, subcutaneous), the time after major surgery or trauma (since pain and opioid requirements are significantly higher in the first $2-3$ postoperative days) (120), as well as other factors affecting one's ability to effectively assess and treat pain in this patient population. PC principles can also help surgeons use multimodal treatment options for the relief of suffering from other physical, psychosocial, and spiritual symptoms, as mentioned above. 
Table 1 Primary surgical palliative care core competencies

Pain and symptom management

- Recognize and define the need for expert palliative care or acute pain management consultation

- Explain the role of co-prescribing acetaminophen, NSAIDs and other non-opioid adjuvants in surgical pain

- Choose the best opioid and administration routes amongst morphine, oxycodone, hydromorphone, and fentanyl, by contextualizing the cause of the patient's pain, the patient's likely duration of pain, and renal or liver insufficiency

- Apply appropriate and safe intravenous (IV) opioid dosing for acute postoperative and posttraumatic pain

- Effectively manage inpatients' IV opioid patient-controlled analgesia (PCA) titrations

- Routinely implement safe and effective strategies to prevent and manage opioid-induced respiratory depression/sedation

- Demonstrate effective conversions of IV opioids to short, renewable courses of PO opioids prior to hospital discharge

- Prescribe effective opioid-induced constipation prevention

- Effectively manage both episodic and persistent nausea

- Delineate the pros and cons of medical (non-operative), procedural, and surgical palliative treatment of terminal malignant bowel obstruction and malignant ascites

- Describe prevention and management principles of postoperative delirium

Ethics and practice of shared decision-making

- Compare shared decision making with directive/paternalistic, facilitative, and informative communication approaches:

$\circ$ Where is the power locus in each?

- Illustrate the practice of each

- Explain the necessary requirements for patient autonomy and how autonomy relates to patient choice

- Illustrate the necessary steps in undertaking shared decision-making

- Justify the minimally-acceptable scope and necessary participants in preoperative surrogate decision maker/HCPOA dialogues

- Describe and implement effective communication to both empower surrogate decision makers and prevent decisional regret and guilt burdens

- Establish appropriate, value-congruent Code/SOTO (scope of treatment order) statuses preoperatively and postoperatively; discuss important details of Code status in the operating room

- Apply patient value-centered shared decision-making ethics to "Perilous Pivot Points" in Perioperative care:

o Preop in high-risk surgery, particularly in frailty and/or patients with life-threatening conditions

- Postop either following complications or with poor outcomes, particularly in the ICU, prior to instituting "rescue" plans

- Any significant disease progression or development of comorbidities, which warrant a re-goaling discussion

Communication skills

- Describe and employ strategies to equalize the power gap between surgeon and patient/family, demonstrating dignity and intellectual and cultural humility for all others

- Employ unbiased curiosity by asking patients and families for their feelings and perspectives, prior to delivering any medical-surgical reports

- Regularly elicit values and explore fears, feasible goals, and unacceptable levels of patient suffering, including unacceptable levels of functional disability and potential discharge locations

- Perform adequate spiritual screening and use further exploration as necessary to assess for sources of meaning and significant spiritual suffering

Table 1 (continued) 
Table 1 (continued)

Communication skills

- Explain the importance of brevity, clarity, reiteration, and sticking to 1-3 messages, and not "thinking out loud" when delivering medical-surgical information

- Demonstrate empathic attendance to emotion using silence and all five letters of the NURSE mnemonic; naming and normalizing ambivalence

- Explain the impact of the words "want" and "treatable" on patient/family conferences

- Contrast the meanings of "hope" and "wish"; demonstrating care when saying each

- Explain the importance of avoiding jargon, numbers, percentages, and misleading double negatives

- Demonstrate asking permission and firing a "warning shot" before delivering poor prognoses

- Demonstrate the honest and compassionate delivery of grave vs. poor prognoses

- Demonstrate effective use of Best Case/Worst Case scenario planning

- Make and explain patient-centered and value-concordant recommendations

- Delineate the necessary elements of time limited trials and when to best apply them

- Recognize when an expert palliative care consultation is needed

Prognostication and surgical planning

- Explain the role of patient/surrogate prognostic awareness in Advance Care Planning

- Assess patients' baseline preoperative physical and cognitive function for frailty; explain the impact of frailty on operative risk calculations

- Outline examples of when Health Care Power of Attorney documents are most needed in surgical patients

- Objectively assess surgical indications: "Is the proposed plan sensible and congruent with the patients' values, fears, and unacceptable treatment burdens?"

- Illustrate the need for preoperative contingency planning with both patients and surrogates, particularly before undertaking high-risk surgery in frail patients; formulating and clearly explaining ethical, value-congruent contingency or "exit strategy" plans preoperatively

- Identify and employ palliative procedures and operations to surgical planning appropriately

- And benefits: comfort care focus, interdisciplinary and bereavement support

End-of-life care

- Recognize when surgical patients' life expectancy is likely short; implementing timely transitions to comfort focused care

- Compare and contrast DNR/Full, DNR/Limited, and DNR/Comfort scope of treatment orders; completing value-congruent POLST forms in appropriate scenarios

- Explain the process of compassionate withdrawal of life-sustaining medical treatments clearly and compassionately

- Evaluate and manage dyspnea, oropharyngeal secretions, and terminal delirium/agitation

Personal and professional growth and integration

- Understand one's personal response to complications and one's preferred preventative and therapeutic management strategies to manage second victimhood and mitigate burnout

- Build emotional and moral resilience by outlining a personal coping plan and identifying personal support people for dealing with vicarious grief from patient loss/complications, and moral injury, meaning/purpose suffering, and relational/professional pain

- Apply effective self-care techniques to increase introspection, self-reflection, self-awareness, and therefore other-focused awareness, humility, and self-compassion

Based primarily on Ref. $(14,74,75,102,103,105,107-110,115)$. 
Some surgical procedures are performed with the primary intention of offering relief of pain and/or suffering. These procedures include but are not limited to intestinal bypass, venting gastrostomy tube placements, diverting ostomies, tumor debulking, PleurX ${ }^{\mathrm{TM}}$ catheter placement (121-123), tracheostomies and feeding tube placements (124-126). An estimated $12.5 \%$ of all surgeries at one comprehensive cancer center were classified as palliative surgeries (127). Cohen and Miner recently reported that palliative procedures performed near the EOL in patients with cancer resulted in an $80 \%$ rate of symptom resolution (57). In their patient subset with gastric outlet obstruction, gastrojejunostomy was associated with a resumption of oral intake in $96 \%$ of patients. Mortality and morbidity rates are significant in patients undergoing palliative procedures and reported mortality rates ranged from $6 \%$ to $11 \%$ and morbidity was in the $30 \%$ range (57).

\section{Ethics and the practice of SDM}

SDM (128-132) and honoring patient autonomy and values are critical concepts for surgeons seeking to provide patient-centered care $(60,133)$. A lack of education or misunderstanding about these ethical concepts frequently contributes to unnecessary patient, family, and surgeon suffering (67). Surgeons may inquire about patient desires, rather than exploring patient values in an actionable way. For example, when physicians ask patients what they "want" in the context of clinical decision-making, this frequently evokes unrealistic "wishes" rather than the values that undergird preferences (134). This style of engagement puts the burden of decision-making on the patient in an "unshared" fashion prior to informed consent as it circumvents the required robust and collaborative acts of SDM. Asking what a patient "wants" inadvertently prompts patients or surrogates to make an immediate choice without the required critical reflection and deliberation that captures patient values and thus ironically thwarts patient-centered autonomy and care (134).

Although SDM is considered the pinnacle of patientcentered care (128), its practical implementation can be challenging (Figure 1). Articulating realistic perioperative prognostic information, particularly in the critical care environment, is an ethical obligation (135) and helps families reframe their expectations about care benefits and burdens. Understanding a patient's values is a key element of SDM $(129,136)$ given that values heavily inform treatment preferences (137). Well-executed autonomy requires reflective-rather than reactive-thinking in the context of SDM (137). Bioengineer, physician, and healthcare analyst Dr. David Eddy was the first to apply a Markov mathematical model to medical decision-making. In his seminal 1990 paper entitled "The Anatomy of a Decision", he claims that medical decisions have two fundamental components: (I) a thoughtful analysis of the evidence; and (II) value judgments regarding the risks and benefits of embarking on various medical/surgical pathways $(138,139)$. Non-directive approaches, such as an informed choice communication style that merely asks a patient what they want, as above, deflects decisions away from patient values (137). SDM processes (Figure 1) ideally conclude with the surgeon offering a value-concordant treatment recommendation (140), which explains how the patient's goals and values are represented and why alternatives to the recommended pathway are value-discordant. This skill is rarely taught in surgical training, but one that is vital in order to aid surgical patients and surrogates through difficult care pathway and treatment decisions.

\section{Communication skills}

Empathetic communication is covered in an accompanying article in this special issue (Lambert); therefore, a comprehensive review will not be undertaken here. PSPC core communication skills include: (I) proffering dignity to all participants and minimizing the surgeon-patient power gap; (II) eliciting patient values and exploring fears, feasible goals, and unacceptable levels of suffering; (III) performing spiritual inquiries; (IV) demonstrating empathic attendance to emotion; (V) taking care with language and focusing on delivering one or two central messages; (VI) the compassionate delivery of an honest prognosis; (VII) making and defending value-concordant treatment recommendations while being familiar with Best Case/Worst Case scenario planning (Figure 2; https://www.youtube.com/ watch?v=FnS3K44sbu0) $(141,142)$, as well as constructing and implementing concretely-defined Time Limited Trials as appropriate (143). Best Case/Worst Case scenario planning was primarily designed for surgeons and highrisk surgical decision-making and this tool is powerfully applied in the setting of clinical uncertainty (144); a setting in which surgeons may "err on the side of operating" even when they predict that the operation is non-beneficial (80).

Language matters. Just as surgeons are advised to avoid euphemisms and the word "want", it is advisable to take 
Shared Decision-Making

Step 1.

Explore patient values, goals, expectations, fears and unacceptable suffering levels

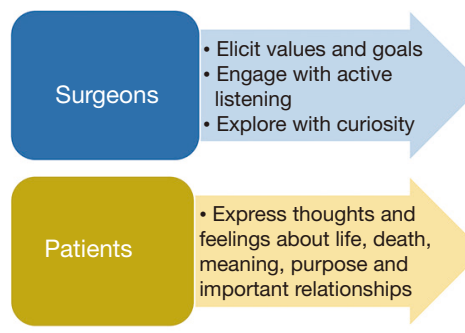
collaborative deliberation
Step 2.

Enmesh care goals with clinical context through

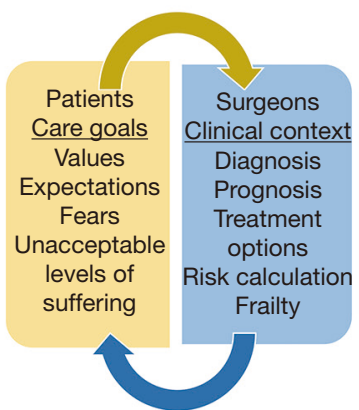

Step 3.

Deliver a patient-centered recommendation

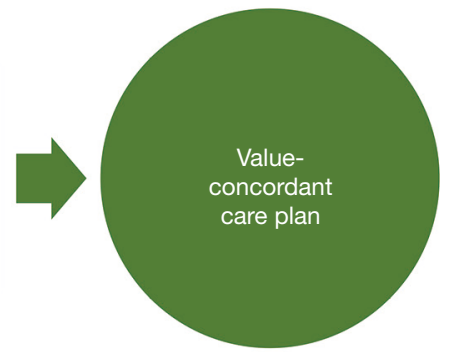

Figure 1 Steps in shared decision-making (SDM).

\begin{tabular}{|c|c|c|c|}
\hline \begin{tabular}{|l|} 
"The best case is a long, $6-10$ \\
hour operation, followed by 5- \\
7 days of intensive care with a \\
breathing tube and maybe \\
dialysis, and $2-3$ weeks in the \\
hospital followed by transition \\
to a nursing home. After this \\
surgery it is unlikely that you \\
would be able to return to living \\
independently, and you will \\
probably need to live the rest of \\
your life in a nursing home." \\
\end{tabular} & Surgery & Palliative Care & $\begin{array}{l}\text { "The best case is that we } \\
\text { admit you to our palliative } \\
\text { care service, they will give } \\
\text { you enough pain meds to } \\
\text { stop the pain in your chest, } \\
\text { your family will come in to } \\
\text { see you, and you live } \\
\text { another } 24-48 \text { hours with } \\
\text { your family at your } \\
\text { bedside. You could possibly } \\
\text { even go home, with } \\
\text { hospice, to die there if we } \\
\text { can control your pain." }\end{array}$ \\
\hline $\begin{array}{l}\text { "Most likely, if we do this long } \\
\text { operation, you will be in } \\
\text { intensive care for } 10-15 \text { days } \\
\text { with a breathing tube and } \\
\text { then need a tracheostomy. } \\
\text { You will need to stay in the } \\
\text { hospital for } 4 \text { to } 6 \text { weeks after } \\
\text { which you might go to } \\
\text { another chronic care hospital } \\
\text { where they care for patients } \\
\text { with a tracheostomy, I think } \\
\text { there is a less than } 10 \% \\
\text { chance that you would live } \\
\text { longer than } 2-3 \text { months after } \\
\text { surgery." } \\
\end{array}$ & & & $\begin{array}{l}\text { "Most likely, we will admit } \\
\text { you to our palliative care } \\
\text { service, they will give you } \\
\text { enough pain meds to stop } \\
\text { the pain. These medicines } \\
\text { could make you very groggy } \\
\text { and unable to talk with } \\
\text { people, and you would die in } \\
\text { a day with your family at } \\
\text { your bedside." } \\
\begin{array}{l}\text { "The worst case is that we } \\
\text { admit you to our palliative }\end{array}\end{array}$ \\
\hline $\begin{array}{l}\text { "The worst case is the long } \\
\text { operation followed by several } \\
\text { weeks in the ICU on a ventilator } \\
\text { but with things like pneumonia, } \\
\text { severe infection, heart attack or } \\
\text { stroke, that ultimately leads to } \\
\text { your death in the ICU." }\end{array}$ & & & $\begin{array}{l}\text { enough pain meds to stop } \\
\text { the pain, the aneurysm } \\
\text { ruptures in a few hours and } \\
\text { you die very suddenly, } \\
\text { possibly with some pain...it } \\
\text { may not be enough time for } \\
\text { all of your family to get here } \\
\text { to see you." }\end{array}$ \\
\hline
\end{tabular}

Figure 2 Best case/worst case scenario planning [(from Ref. (141)].

great care when saying "hope", which is a word that can unintentionally perpetuate false, unrealistic "wishes" on the part of patients, surrogates, and surgeons alike (145). Similarly, "physician use of the word 'treatable' may lead patients or surrogates to derive unwarranted good news and false (bope) to pursue treatment, even when physicians have explicitly stated information to the contrary." (146). Surgeons may also unintentionally lead patients and families toward their own personal goals, without discovering the patient's values that should undergird care decisions (89).

It is imperative to determine what matters most to patients from them directly, their loved ones, or a combination of the two $(136,147)$. Merely applying patient decision aids to surgical risk calculations are inadequate (148). 
Abstract patient values must be elicited (59,60,149-152) and concatenated with evidence-based clinical knowledge, such as prognosis and risk calculations, for surgical decisions to be truly shared $(67,148)$. Responding to patient/family emotion should occur throughout all conversations. The NURSE mnemonic is particularly helpful in this regard. Surgeons can Name, Understand, Respect, Support, and Explore expressed emotion, normalizing and affirming the heart-wrenching nature of these decisions. Barriers to good communication and recommendations for how to overcome them have been published in the surgical literature $(153,154)$. Many pitfalls lay in wait for surgeons who courageously embark on conversations that include the possibility of the end of their patient's life. The use of medical jargon with most nonmedical patients widens the power and communication gap and is to be avoided (155). Perhaps surprisingly, wellintentioned patient education, which delivers knowledge to patients and surrogates up front, particularly when technical medical terms and/or population percentages are voiced prior to discerning patient values, can be counterproductive and is an ineffective method to develop rapport (156). In contrast, what most patients and families are desperate for is for their surgeon to empathically partner with them (157).

\section{Prognostication and surgical planning}

A prognosis is a prediction of possible future outcomes of a treatment or a disease course based on medical knowledge and experience. Prognosis influences goals of care and the medical decision-making process that transpires as clinical courses change over time. Prognosis includes not only estimates of time remaining but also functional and cognitive abilities and/or decline (158). Strategies for assessing and conveying prognosis depend on the place of care and acuity of the clinical case. An EOL discussion in the ICU with a surrogate decision maker after an unanticipated traumatic event will be conducted differently than a similar discussion in the outpatient clinic setting, with a patient who has an advanced cancer diagnosis (159). In either scenario, Paladino et al. write, "Sharing prognosis with patients is about more than expected survival. The experience of serious illness includes multiple dimensions, encompassing anticipated changes to QOL, functional abilities and activities, the possibility of unpredictable events, and patients' (and families') own hopes, fears, and expectations about the future" (160). Honest prognostication allows families time for preparedness planning that supports the need for profoundly meaningful communication (161); including expressing love, gratitude, forgiveness, and saying "goodbye" (162); an opportunity that is missed when prognosis is not discussed with realism (163). When this opportunity is missed, family members experience more survivor guilt, anxiety, depression, and post-traumatic stress symptoms $(70,71,158)$, as well as complicated grief $(72,73)$. Glare and Sinclair pen "Optimism of prognostication as perceived by patients may lead to the requesting of medical treatment that would not be chosen if a more accurate and realistic prognosis was formulated and clearly communicated." (164).

Whether a patient's future is hours or months, it is helpful to have a framework for assessing and communicating a patient's prognosis and surgeons are advised to do their prognostication "homework" prior to initiating these discussions. First, the patient/family's current understanding of the situation must be assessed. Taking a few minutes to understand where they're at helps the surgeon gain important information about perceptions as well as any unrealistic expectations. By seeking first to understand what the patient or their surrogate knows, surgeons can direct the conversation appropriately. For instance, does the patient/ family already know most of the information you have to share, or do you have a significant amount of ground to cover in order to ensure that you are starting on the same page? British neurosurgeon Henry Marsh, in "Do No Harm: Stories of Life, Death, and Brain Surgery", explains how important a surgeons' approach at such perilous junctures is in the context of a representative patient's question: "Is it cancer?" Marsh says, "This is always a critical point of such conversations. I have to decide whether to commit myself to a long and painful exchange, or talk in ambiguities, euphemisms and obscure technical language and leave quickly, untouched and uncontaminated by the patient's suffering and illness." (165).

The authors of this review have identified three "Perilous Pivot-Points" in surgical patients' clinical trajectories, all of which dramatically impact surgical planning and warrant accurate prognosis delivery and value clarification as well as good communication skills in order to support patients and families with a framework in the SDM process: (I) preoperatively when entertaining high-risk surgery and/or in the context of life-threatening disease, frailty or geriatrics; (II) postoperatively following complications, other sentinel events (such as return to the ICU), poor outcomes, and prior to instituting any rescue plans, including tracheostomy, gastrostomy tube placement, renal replacement therapy, or return to the operating room; (III) with disease progression, such as in cancer or medical comorbidities, which warrant a 
Prognostication and Surgical Planning
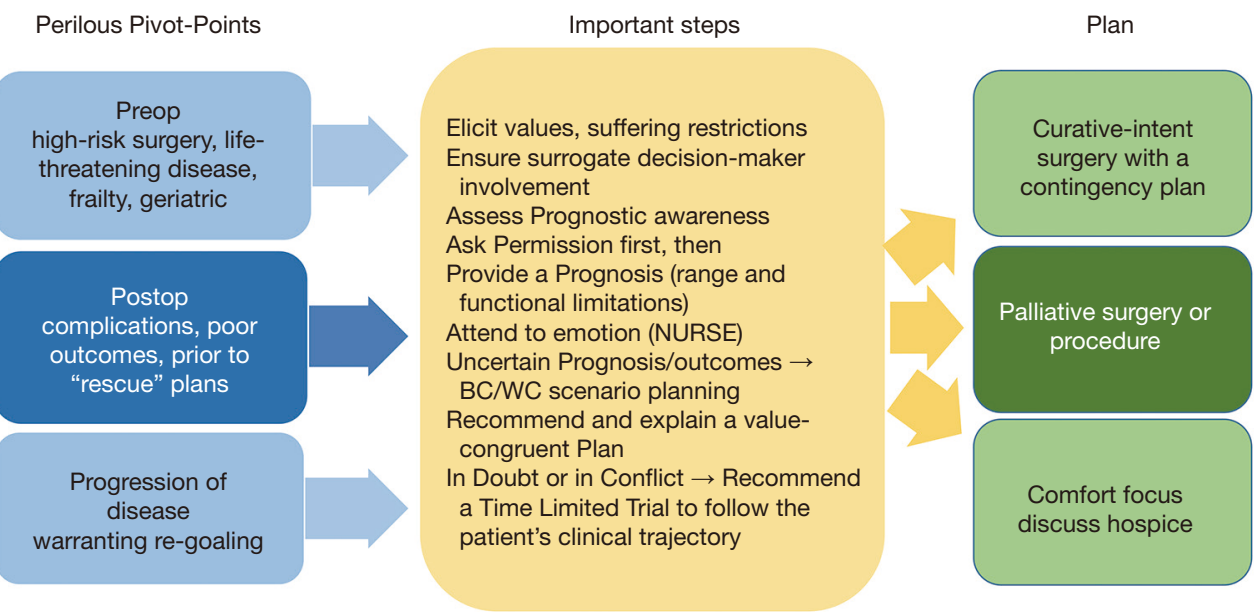

Figure 3 Perilous Pivot-Points in prognostication and surgical planning.

re-goaling conversation (Figure 3).

Surgeons may begin an operation with curative intent, only to find that is unattainable. Palliative surgical principles are commonly employed in these "Plan B" scenarios, and necessitate prior knowledge of the patient's values and unacceptable degrees of suffering, as mentioned above. Such preoperative contingency plans are best discussed explicitly with both patients and their surrogate decision-maker before the patient is anesthetized and intubated if there is any suspicion that conversion to a palliative procedure is likely.

\section{End-of-life care}

Surgeons are commonly faced with the care of dying patients. For patients with life-threatening surgical illness, important discussions are needed that face the issue of how death is likely to occur, rather than if death will occur (166). Surgeons often recognize when operations may be futile (80) and report maintaining LSMTs and a cascade of non-beneficial and/ or value-incongruent treatment modalities (167). Thus, the application of PSPC principles in the ICU is of paramount importance $(30,158)$. Competency for many aspects of EOL care, including the clinical steps and ethical principles of withdrawing LSMTs, the use of sedatives, analgesics, anxiolytics, antisecretory agents and nonpharmacologic approaches to ease suffering during the dying process (158). Additionally, the ethical concepts important in guiding EOL care, including the distinctions between withholding or withdrawing treatments and between primarily intended beneficent goals versus harm that is merely foreseen (the principle of double effect) (168). When discussions about withholding, non-escalation, or withdrawal of LSMTs are undertaken, surgeons should reiterate that no one is giving up on the patient and that most importantly care is ongoing. Allowing a patient to die naturally with comfort focused care is not meant to degrade the value of the patient's life or their worthiness, but rather emphasize their dignity to the fullest extent possible $(161,169)$. In these most demanding of times, surgeons must remind families that everyone is returning to what matters most. By revering the patient's most dearly held values and honoring their dignity and legacy it is these aspects of care that have the ability to transcend concerns about "giving up".

Caring for the dying, being present, and facilitating new meaning-making during another's suffering is emotionally trying and spiritually challenging. And yet, this work offers opportunities for spiritual and professional growth (170-172), as well as deep personal rewards (173). The gratitude expressed by patients and families is profound and priceless. As Susan Block says: "The intimacy of the experience offers deeper understanding about the nature of life, an appreciation of the gift of being alive, and constantly renewed inspiration and hopefulness about buman resilience." (174).

\section{Personal and professional growth and integration}

Surgeons' inclinations to be introspective has been questioned (175). This perceived reluctance may exacerbate the severity of moral distress, second victim syndrome (176), disenfranchised grief from patient loss (177), emotionally 
haunting experiences (178), and burnout (179-182). A recent review concluded that "surgeons' emphasis on technical aspects, individuality, and performance seems to impede a modern patient-centered approach to care and to act as a barrier to well-being" (183). This techniqueorientation over people-orientation problem (94) is a manifestation of traditions, surgical culture, and the training process, which will require significant reform on the part of surgical leadership to overcome (184).

The ability of surgeons to listen and effectively communicate suffers when they experience moral distress (185). Moral distress is distinct from ethical quandaries; it typically manifests as debilitating feelings of disgust, frustration, sadness, anger, helplessness, threatening one's self-identity, value, integrity and/or beliefs (186), and usually stems from powerlessness to affect a situation that one deems to be unethical $(187,188)$. Most $(87 \%$ of $)$ surveyed neurosurgery residents reported moral distress, saying that they "participated in operations and worried whether surgery aligned with patient goals" (28). Untended moral distress is a leading cause of burnout (189); some physician trainees who feel obligated to perform futile treatments near the EOL develop detached, dehumanizing attitudes that characterize burned-out moral distress (190). Second victim syndrome can occur when a surgeon holds themselves responsible for complications (typically intraoperative) and deaths (191).

The management of second victim syndrome and mitigation of burnout $(177,192)$ includes promotion of emotional management (193), ethics education, creating safe spaces for honest interchange $(194,195)$ with peers and mentors (196), and coaching $(197,198)$. Mindfulness-based interventions have proven to help healthcare professionals build moral resilience and gain a greater comfort being present with dying. The application of mindfulness-based interventions can increase introspection, reflection, selfawareness, empathy (188,199-204), metacognition, and meaning reconstruction $(205,206)$. Physical self-care, such as exercise, balance and relaxation, nourishment, and sleep maintenance, as well as recreational self-care, such as spending time outdoors, engaging in hobbies and having fun, as well as spiritual, creative, and social practices that increase meaning-making and bonding have all been shown to mitigate stress and elevate well-being in medical students $(207,208)$. All these efforts can foster surgeons' personal and professional growth and integration. Perhaps surprisingly, empathy protects against burnout (209), a phenomenon that supports the empathic partnering competencies for practicing PSPC. A surgeons' attendance to their own emotions (210) may be the best first step toward self-care $(193,211,212)$, which promotes personal and professional growth and the integration thereof.

\section{Conclusions}

As demonstrated above, integrating palliative care practices into routine surgical care for seriously ill surgical patients is both possible and beneficial. The need for improved pain and symptom management as well as SDM amongst surgical ICU patients and those undergoing surgical intervention for high-risk emergency operations, particularly in frail patients, advanced cancer and traumatic injuries cannot be overstated. Professional societies, including the American College of Surgeons and the Eastern Association for the Surgery of Trauma, have endorsed that surgeons should be proficient at providing PSPC for seriously ill and injured surgical patients, and surgical trainees are now expected to demonstrate competencies in most if not all of the fundamental skills that delineate PPC. Our six proposed PSPC proficiencies include: (I) pain and symptom management, (II) the ethics and practice of SDM, (III) communication skills, (IV) prognostication and surgical planning, (V) end-of-life care, and (VI) personal and professional growth and integration as competence in each of these core areas is central to skillfully providing PSPC.

\section{Acknowledgments}

The authors thank Nicole Segalini for her assistance with formatting Table 1.

Funding: None.

\section{Footnote}

Provenance and Peer Review: This article was commissioned by the Guest Editors (Fabian M. Johnston and Ana Berlin) for the series "Palliative Care and Surgery" published in Annals of Palliative Medicine. The article has undergone external peer review.

Reporting Checklist: The authors have completed the Narrative Review reporting checklist (available at https:// apm.amegroups.com/article/view/10.21037/apm-21-369/rc).

Conflicts of Interest: All authors have completed the ICMJE uniform disclosure form (available at https://apm. 
amegroups.com/article/view/10.21037/apm-21-369/coif). The series "Palliative Care and Surgery" was commissioned by the editorial office without any funding or sponsorship. The authors have no other conflicts of interest to declare.

Ethical Statement: The authors are accountable for all aspects of the work in ensuring that questions related to the accuracy or integrity of any part of the work are appropriately investigated and resolved.

Open Access Statement: This is an Open Access article distributed in accordance with the Creative Commons Attribution-NonCommercial-NoDerivs 4.0 International License (CC BY-NC-ND 4.0), which permits the noncommercial replication and distribution of the article with the strict proviso that no changes or edits are made and the original work is properly cited (including links to both the formal publication through the relevant DOI and the license). See: https://creativecommons.org/licenses/by-nc-nd/4.0/.

\section{References}

1. Sigman, M, Miller, P. Practicing primary palliative care: A call to action. Bull Am Coll Surg 2019;104:13-21.

2. Dunn GP. Surgical palliative care: recent trends and developments. Surg Clin North Am 2011;91:277-92.

3. Dunn GP, Johnson AG, editors. Surgical Palliative Care. Oxford, New York: Oxford University Press, 2004.

4. Rhee $\mathrm{C}, \mathrm{McHugh} \mathrm{M}$, Tun $\mathrm{S}$, et al. Advantages and Challenges of an Interdisciplinary Palliative Care Team Approach to Surgical Care. Surg Clin North Am 2019;99:815-21.

5. Miller P. Surgical Palliative Care-Where Are We in 2020? Am Surg 2020;86:1436-40.

6. Hawley PH. The bow tie model of 21 st century palliative care. J Pain Symptom Manage 2014;47:e2-5.

7. Cooper Z, Lilley EJ, Bollens-Lund E, et al. High Burden of Palliative Care Needs of Older Adults During Emergency Major Abdominal Surgery. J Am Geriatr Soc 2018;66:2072-8.

8. Berlin A, Carleton TJ. Concurrent Palliative Care for Surgical Patients. Surg Clin North Am 2019;99:823-31.

9. Bateni SB, Canter RJ, Meyers FJ, et al. Palliative Care Training and Decision-Making for Patients with Advanced Cancer: A Comparison of Surgeons and Medical Physicians. Surgery 2018. [Epub ahead of print]. doi: 10.1016/j.surg.2018.01.021.

10. Buchman TG. Surgeons and their patients near the end of life. Crit Care Med 2010;38:995-6.

11. Paul Olson TJ, Schwarze ML. Failure-to-pursue Rescue: Truly a Failure? Ann Surg 2015;262:e43-4.

12. Buchman TG, Cassell J, Ray SE, et al. Who should manage the dying patient? Rescue, shame, and the surgical ICU dilemma. J Am Coll Surg 2002;194:665-73.

13. Aslakson R, Cheng J, Vollenweider D, et al. Evidencebased palliative care in the intensive care unit: a systematic review of interventions. J Palliat Med 2014;17:219-35.

14. National Consensus Project for Quality Palliative Care. Clinical Practice Guidelines for Quality Palliative Care, 4th edition. Richmond, VA: National Coalition for Hospice and Palliative Care; 2018. Available online: https://www.nationalcoalitionhpc.org/wp-content/ uploads/2018/10/NCHPC-NCPGuidelines_4thED_web_ FINAL.pdf

15. Miller P. The Time Is Always Right to Do What Is Right for Our Patients. Surg Clin North Am 2019;99:xix-xxiii.

16. Ellis H, Abdalla S. A History of Surgery [Internet]. Third Edition. Boca Raton, FL: CRC Press; 2018. Available online: https://www.taylorfrancis.com/books/historysurgery-harold-ellis-sala-abdalla/10.1201/9780429461743

17. Hall DE. Reimagining Surgical Success-Caring for Those Who Die Despite Our Best Efforts. JAMA Surg 2020;155:146-7.

18. Temel JS, Greer JA, Muzikansky A, et al. Early palliative care for patients with metastatic non-small-cell lung cancer. N Engl J Med 2010;363:733-42.

19. Amini A, Miura JT, Larrieux G, et al. Palliative care training in surgical oncology and hepatobiliary fellowships: a national survey of the fellows. Ann Surg Oncol 2015;22:1761-7.

20. Bonanno AM, Kiraly LN, Siegel TR, et al. Surgical palliative care training in general surgery residency: An educational needs assessment. Am J Surg 2019;217:928-31.

21. Wancata LM, Hinshaw DB, Suwanabol PA. Palliative Care and Surgical Training: Are We Being Trained to Be Unprepared? Ann Surg 2017;265:32-3.

22. Weissman DE, Meier DE. Identifying patients in need of a palliative care assessment in the hospital setting: a consensus report from the Center to Advance Palliative Care. J Palliat Med 2011;14:17-23.

23. Workforce Statistics. AAHPM: American Academy of Hospice and Palliative Medicine. Available online: http:// aahpm.org/career/workforce-study\#HPMphysicians

24. The National Academies of Science Engineering and Medicine. Building the Workforce We Need to Care for People with Serious Illness: Proceedings of a Workshop. 
Washington, DC: The National Academies Press, 2020.

Available online: https://www.nap.edu/read/25789/ chapter/1

25. Quill TE, Abernethy AP. Generalist plus specialist palliative care--creating a more sustainable model. N Engl J Med 2013;368:1173-5.

26. Kamal AH, Bull JH, Swetz KM, et al. Future of the Palliative Care Workforce: Preview to an Impending Crisis. Am J Med 2017;130:113-4.

27. Committee on Approaching Death: Addressing Key End of Life Issues. Institute of Medicine Committee on Approaching Death: Addressing Key End-of-Life Issues. In: Dying in America: Improving Quality and Honoring Individual Preferences Near the End of Life. Washington, DC: National Academies Press, 2015. Available online: https://www.ncbi.nlm.nih.gov/books/NBK285678/

28. Miranda SP, Schaefer KG, Vates GE, et al. Palliative Care and Communication Training in Neurosurgery Residency: Results of a Trainee Survey. J Surg Educ 2019;76:1691-702.

29. Adolph MD. Inpatient palliative care consultation: enhancing quality of care for surgical patients by collaboration. Surg Clin North Am 2011;91:317-24, viii.

30. Dunn GP, Mosenthal AC. Palliative care in the surgical intensive care unit: where least expected, where most needed. Asian J Surg 2007;30:1-5.

31. Karlekar M, Collier B, Parish A, et al. Utilization and determinants of palliative care in the trauma intensive care unit: results of a national survey. Palliat Med 2014;28:1062-8.

32. Rodriguez R, Marr L, Rajput A, et al. Utilization of palliative care consultation service by surgical services. Ann Palliat Med 2015;4:194-9.

33. Scally CP, Robinson K, Blumenthaler AN, et al. Identifying Core Principles of Palliative Care Consultation in Surgical Patients and Potential Knowledge Gaps for Surgeons. J Am Coll Surg 2020;231:179-85.

34. Aslakson RA, Chandrashekaran SV, Rickerson E, et al. A Multicenter, Randomized Controlled Trial of Perioperative Palliative Care Surrounding Cancer Surgery for Patients and Their Family Members (PERIOP-PC). J Palliat Med 2019;22:44-57.

35. Chatterjee K, Harrington S, Sexton K, et al. Impact of Palliative Care Utilization for Surgical Patients Receiving Prolonged Mechanical Ventilation: National Trends (20092013). Jt Comm J Qual Patient Saf 2020;46:493-500.

36. Gani F, Enumah ZO, Conca-Cheng AM, et al. Palliative Care Utilization among Patients Admitted for
Gastrointestinal and Thoracic Cancers. J Palliat Med 2018;21:428-37.

37. Evans BA, Turner MC, Gloria JN, et al. Palliative Care Consultation Is Underutilized in Critically Ill General Surgery Patients. Am J Hosp Palliat Care 2020;37:149-53.

38. Maerz LL, Mosenthal AC, Miller RS, et al. Futility and the acute care surgeon. J Trauma Acute Care Surg 2015;78:1216-9.

39. Liu S, Heller DR, Jean RA, et al. Palliative care is underutilized and affects healthcare costs in ruptured abdominal aortic aneurysms. Surgery 2020;168:234-6.

40. Lilley EJ, Khan KT, Johnston FM, et al. Palliative Care Interventions for Surgical Patients: A Systematic Review. JAMA Surg 2016;151:172-83.

41. Lee CW, Vitous CA, Silveira MJ, et al. Delays in Palliative Care Referral Among Surgical Patients: Perspectives of Surgical Residents Across the State of Michigan. J Pain Symptom Manage 2019;57:1080-1088.e1.

42. Cocanour CS. End-of-life care in trauma. J Trauma Acute Care Surg 2015;79:891-6.

43. Han SM, Gasper WJ, Chuter TA. Endovascular rescue after inadvertent false lumen stent graft implantation. J Vasc Surg 2016;63:518-22.

44. Lin HS, Watts JN, Peel NM, et al. Frailty and postoperative outcomes in older surgical patients: a systematic review. BMC Geriatr 2016;16:157.

45. Makhani SS, Kim FY, Liu Y, et al. Cognitive Impairment and Overall Survival in Frail Surgical Patients. J Am Coll Surg 2017;225:590-600.e1.

46. Mrdutt MM, Papaconstantinou HT, Robinson BD, et al. Preoperative Frailty and Surgical Outcomes Across Diverse Surgical Subspecialties in a Large Health Care System. J Am Coll Surg 2019;228:482-90.

47. Saxton A, Velanovich V. Preoperative frailty and quality of life as predictors of postoperative complications. Ann Surg 2011;253:1223-9.

48. Schwarze ML, Barnato AE, Rathouz PJ, et al. Development of a list of high-risk operations for patients 65 years and older. JAMA Surg 2015;150:325-31.

49. Shah R, Attwood K, Arya S, et al. Association of Frailty With Failure to Rescue After Low-Risk and High-Risk Inpatient Surgery. JAMA Surg 2018;153:e180214.

50. Shinall MC Jr, Arya S, Youk A, et al. Association of Preoperative Patient Frailty and Operative Stress With Postoperative Mortality. JAMA Surg 2020;155:e194620.

51. Tang VL, Jing B, Boscardin J, et al. Association of Functional, Cognitive, and Psychological Measures With 1-Year Mortality in Patients Undergoing Major Surgery. 
JAMA Surg 2020;155:412-8.

52. Velanovich V, Antoine H, Swartz A, et al. Accumulating deficits model of frailty and postoperative mortality and morbidity: its application to a national database. J Surg Res 2013;183:104-10.

53. Udelsman BV, Lilley EJ, Qadan M, et al. Deficits in the Palliative Care Process Measures in Patients with Advanced Pancreatic Cancer Undergoing Operative and Invasive Nonoperative Palliative Procedures. Ann Surg Oncol 2019;26:4204-12.

54. Ho VP, Schiltz NK, Reimer AP, et al. High-Risk Comorbidity Combinations in Older Patients Undergoing Emergency General Surgery. J Am Geriatr Soc 2019;67:503-10.

55. Lilley EJ, Cooper Z. The High Burden of Palliative Care Needs among Older Emergency General Surgery Patients. J Palliat Med 2016;19:352-3.

56. Cauley CE, Panizales MT, Reznor G, et al. Outcomes after emergency abdominal surgery in patients with advanced cancer: Opportunities to reduce complications and improve palliative care. J Trauma Acute Care Surg 2015;79:399-406.

57. Cohen JT, Miner TJ. Patient selection in palliative surgery: Defining value. J Surg Oncol 2019;120:35-44.

58. Miner TJ. Understanding the Core Principles of Primary and Specialty Surgical Palliative Care. J Am Coll Surg 2020;231:185-6.

59. Scheunemann LP, Arnold RM, White DB. The facilitated values history: helping surrogates make authentic decisions for incapacitated patients with advanced illness. Am J Respir Crit Care Med 2012;186:480-6.

60. Naik AD, Martin LA, Moye J, et al. Health Values and Treatment Goals of Older, Multimorbid Adults Facing LifeThreatening Illness. J Am Geriatr Soc 2016;64:625-31.

61. Steinhauser KE, Christakis NA, Clipp EC, et al. Factors considered important at the end of life by patients, family, physicians, and other care providers. JAMA 2000;284:2476-82.

62. Singer PA, Martin DK, Kelner M. Quality end-of-life care: patients' perspectives. JAMA 1999;281:163-8.

63. Nabozny MJ, Kruser JM, Steffens NM, et al. Patientreported Limitations to Surgical Buy-in: A Qualitative Study of Patients Facing High-risk Surgery. Ann Surg 2017;265:97-102.

64. Scheunemann LP, Ernecoff NC, Buddadhumaruk P, et al. Clinician-Family Communication About Patients' Values and Preferences in Intensive Care Units. JAMA Intern Med 2019;179:676-84.
65. Balboni TA, Balboni MJ. The Spiritual Event of Serious Illness. J Pain Symptom Manage 2018;56:816-22.

66. Moadel A, Morgan C, Fatone A, et al. Seeking meaning and hope: self-reported spiritual and existential needs among an ethnically-diverse cancer patient population. Psychooncology 1999;8:378-85.

67. Marterre B, Shin J, Terzian WTH. Shared DecisionMaking in the Context of Uncertain Care Goals and Outcomes: Dissecting a Penetrating Abdominal Trauma Case Complicated by Enterocutaneous Fistulae. Am Surg 2020;86:1456-61.

68. Buchanan AE, Brock DW. Deciding for Others: The Ethics of Surrogate Decision Making. Cambridge: Cambridge University Press, 2008.

69. Macauley RC. Ethics in Palliative Care: A Complete Guide. New York, NY: Oxford University Press, 2018.

70. Pochard F, Darmon M, Fassier T, et al. Symptoms of anxiety and depression in family members of intensive care unit patients before discharge or death. A prospective multicenter study. J Crit Care 2005;20:90-6.

71. Azoulay E, Pochard F, Kentish-Barnes N, et al. Risk of post-traumatic stress symptoms in family members of intensive care unit patients. Am J Respir Crit Care Med 2005;171:987-94.

72. Tyrie LS, Mosenthal AC. Care of the family in the surgical intensive care unit. Dunn GP, editor. Surg Clin North Am 2011;91:333-42.

73. Nelson JE, Puntillo KA, Pronovost PJ, et al. In their own words: patients and families define high-quality palliative care in the intensive care unit. Crit Care Med 2010;38:808-18.

74. Ahluwalia SC, Chen C, Raaen L, et al. A Systematic Review in Support of the National Consensus Project Clinical Practice Guidelines for Quality Palliative Care, Fourth Edition. J Pain Symptom Manage 2018;56:831-70.

75. Palliation as a core surgical principle: part 2. J Am Coll Surg 2004;199:321-34.

76. Krizek TJ. Spiritual dimensions of surgical palliative care. Surg Oncol Clin N Am 2001;10:39-55.

77. Marterre B, Clayville K. Navigating the Murky Waters of Hope, Fear, and Spiritual Suffering: An Expert CoCaptain's Guide. Surg Clin North Am 2019;99:991-1018.

78. King SD, Fitchett G, Murphy PE, et al. Determining best methods to screen for religious/spiritual distress. Support Care Cancer 2017;25:471-9.

79. Rubin EB, Buehler A, Halpern SD. Seriously Ill Patients' Willingness to Trade Survival Time to Avoid High Treatment Intensity at the End of Life. JAMA Intern Med 
2020;180:907-9.

80. Morris RS, Ruck JM, Conca-Cheng AM, et al. Shared Decision-Making in Acute Surgical Illness: The Surgeon's Perspective. J Am Coll Surg 2018;226:784-95.

81. Sonntag EA, Shah KB, Katz JN. Educating Resident and Fellow Physicians on the Ethics of Mechanical Circulatory Support. AMA J Ethics 2019;21:E407-415.

82. Kruser JM, Cox CE, Schwarze ML. Clinical Momentum in the Intensive Care Unit. A Latent Contributor to Unwanted Care. Ann Am Thorac Soc 2017;14:426-31.

83. McCahill LE, Krouse RS, Chu DZ, et al. Decision making in palliative surgery. J Am Coll Surg 2002;195:411-22; discussion 422-3.

84. Angelos P. Responding to patient requests to withdraw life support: surgical ethics and responsibility. Ann Surg 2012;256:16-7.

85. Schwarze ML, Redmann AJ, Brasel KJ, et al. The role of surgeon error in withdrawal of postoperative life support. Ann Surg 2012;256:10-5.

86. Christensen JF, Levinson W, Dunn PM. The heart of darkness: the impact of perceived mistakes on physicians. J Gen Intern Med 1992;7:424-31.

87. Huston-Paterson H, Hatchimonji JS, Ganta N, et al. Surgical complications can bias surgeons from timely recognition of a patient's imminent death. J Am Coll Surg 2019;229:S122-3.

88. McGreevy CM, Bryczkowski S, Pentakota SR, et al. Unmet palliative care needs in elderly trauma patients: can the Palliative Performance Scale help close the gap? Am J Surg 2017;213:778-84.

89. Nelson JE, Curtis JR, Mulkerin C, et al. Choosing and using screening criteria for palliative care consultation in the ICU: a report from the Improving Palliative Care in the ICU (IPAL-ICU) Advisory Board. Crit Care Med 2013;41:2318-27.

90. Mosenthal AC, Murphy PA. Interdisciplinary model for palliative care in the trauma and surgical intensive care unit: Robert Wood Johnson Foundation Demonstration Project for Improving Palliative Care in the Intensive Care Unit. Crit Care Med 2006;34:S399-403.

91. Finkelstein M, Goldstein NE, Horton JR, et al. Developing triggers for the surgical intensive care unit for palliative care integration. J Crit Care 2016;35:7-11.

92. Wilson DG, Harris SK, Peck H, et al. Patterns of Care in Hospitalized Vascular Surgery Patients at End of Life. JAMA Surg 2017;152:183-90.

93. Nabozny MJ, Barnato AE, Rathouz PJ, et al. Trajectories and Prognosis of Older Patients Who Have Prolonged
Mechanical Ventilation After High-Risk Surgery. Crit Care Med 2016;44:1091-7.

94. Borges NJ, Osmon WR. Personality and medical specialty choice: technique orientation versus people orientation. J Vocat Behav 2001;58:22-35.

95. Baimas-George M, Vrochides D. The Sorting Hat of Medicine: Why Hufflepuffs Wear Stethoscopes and Slytherins Carry Scalpels. J Surg Educ 2020;77:772-8.

96. Schwarze ML, Brasel KJ, Mosenthal AC. Beyond 30-day mortality: aligning surgical quality with outcomes that patients value. JAMA Surg 2014;149:631-2.

97. Bradley C, Weaver J, Brasel K. Addressing access to palliative care services in the surgical intensive care unit. Surgery 2010;147:871-7.

98. Shinall MC Jr, Hoskins A, Hawkins AT, et al. A randomized trial of a specialist palliative care intervention for patients undergoing surgery for cancer: rationale and design of the Surgery for Cancer with Option of Palliative Care Expert (SCOPE) Trial. Trials 2019;20:713.

99. Yefimova M, Aslakson RA, Yang L, et al. Palliative Care and End-of-Life Outcomes Following High-risk Surgery. JAMA Surg 2020;155:138-46.

100. Olmsted CL, Johnson AM, Kaboli P, et al. Use of palliative care and hospice among surgical and medical specialties in the Veterans Health Administration. JAMA Surg 2014;149:1169-75.

101.Kwok AC, Semel ME, Lipsitz SR, et al. The intensity and variation of surgical care at the end of life: a retrospective cohort study. Lancet 2011;378:1408-13.

102. Task Force on Surgical Palliative care; Committee on Ethics. Statement of principles of palliative care. Bull Am Coll Surg 2005;90:34-5.

103. Trauma Quality Improvement Program. ACS TQIP Palliative Care Best Practice Guidelines. American College of Surgeons; 2017 Oct. Available online: https:// www.facs.org/-/media/files/quality-programs/trauma/tqip/ palliative_guidelines.ashx

104.Aziz HA, Lunde J, Barraco R, et al. Evidence-based review of trauma center care and routine palliative care processes for geriatric trauma patients; A collaboration from the American Association for the Surgery of Trauma Patient Assessment Committee, the American Association for the Surgery of Trauma Geriatric Trauma Committee, and the Eastern Association for the Surgery of Trauma Guidelines Committee. J Trauma Acute Care Surg 2019;86:737-43.

105.Dans M, Smith T, Back A, et al. NCCN Guidelines Insights: Palliative Care, Version 2.2017. J Natl Compr 
Canc Netw 2017;15:989-97.

106. Ferrell BR, Temel JS, Temin S, et al. Integration of Palliative Care Into Standard Oncology Care: American Society of Clinical Oncology Clinical Practice Guideline Update. J Clin Oncol 2017;35:96-112.

107.ACGME. Surgery Milestones. The Accreditation Council for Graduate Medical Education; 2019 Jan. Available online: http://www.acgme.org/portals/0/pdfs/milestones/ surgerymilestones.pdf

108. Surgical Council on Resident Education. SCORE 20202021: Curriculum Outline for General Surgery. Available online: http://files.surgicalcore.org/2020-2021_GS_CO_ Booklet_v3editsfinal.pdf

109. The American Board of Surgery. SCORE Curriculum Outline. Available online: https://www.absurgery.org/ default.jsp?scre_booklet

110.Dunn GP, Martensen R, Weissman D, editors. Surgical Palliative Care: A Resident's Guide. Chicago, IL: American College of Surgeons, 2009. Available online: https:// www.facs.org/ /media/files/education/palliativecare/ surgicalpalliativecareresidents.ashx

111.Dunn GP. Principles and core competencies of surgical palliative care: an overview. Otolaryngol Clin North Am 2009;42:1-13, vii.

112. Suwanabol PA, Kanters AE, Reichstein AC, et al. Characterizing the Role of U.S. Surgeons in the Provision of Palliative Care: A Systematic Review and MixedMethods Meta-Synthesis. J Pain Symptom Manage 2018;55:1196-1215.e5.

113. Klaristenfeld DD, Harrington DT, Miner TJ. Teaching palliative care and end-of-life issues: a core curriculum for surgical residents. Ann Surg Oncol 2007;14:1801-6.

114. Bradley CT, Brasel KJ. Core competencies in palliative care for surgeons: interpersonal and communication skills. Am J Hosp Palliat Care 2007;24:499-507.

115.Lee KC, Walling AM, Senglaub SS, et al. Improving Serious Illness Care for Surgical Patients: Quality Indicators for Surgical Palliative Care. Ann Surg 2020. [Epub ahead of print]. doi: 10.1097/ SLA.0000000000003894.

116. Miller P, Hauser JM. EPEC-Surgery. Chicago, IL, 2019. Available online: https://www.scholars.northwestern.edu/ en/projects/education-in-palliative-and-end-of-life-careepec-surgery-program-4

117. Oya H, Matoba M, Murakami S, et al. Mandatory palliative care education for surgical residents: initial focus on teaching pain management. Jpn J Clin Oncol 2013;43:170-5.
118. Harbaugh CM, Suwanabol PA. Optimizing Pain Control During the Opioid Epidemic. Surg Clin North Am 2019;99:867-83.

119.Zens TJ, Kopecky KE, Schwarze ML, et al. Surgery Hurts: Characterizing the Experience of Pain in Surgical Patients as Witnessed by Medical Students. J Surg Educ 2019;76:1506-15.

120. Harvin JA, Albarado R, Truong VTT, et al. Multi-Modal Analgesic Strategy for Trauma: A Pragmatic Randomized Clinical Trial. J Am Coll Surg 2021;232:241-251.e3.

121. Richard HM 3rd, Coldwell DM, Boyd-Kranis RL, et al. Pleurx tunneled catheter in the management of malignant ascites. J Vasc Interv Radiol 2001;12:373-5.

122. Hodge C, Badgwell BD. Palliation of malignant ascites. J Surg Oncol 2019;120:67-73.

123. Paul Olson TJ, Pinkerton C, Brasel KJ, et al. Palliative surgery for malignant bowel obstruction from carcinomatosis: a systematic review. JAMA Surg 2014;149:383-92.

124.McGreevy CM, Pentakota SR, Mohamed O, et al. Gastrostomy tube placement: An opportunity for establishing patient-centered goals of care. Surgery 2017;161:1100-7.

125.Hoffman MR. Tracheostomies and PEGs: When Are They Really Indicated? Surg Clin North Am 2019;99:955-65.

126. Chan T, Devaiah AK. Tracheostomy in palliative care. Otolaryngol Clin North Am 2009;42:133-41, x.

127. Krouse RS, Nelson RA, Farrell BR, et al. Surgical palliation at a cancer center: incidence and outcomes. Arch Surg 2001;136:773-8.

128. Barry MJ, Edgman-Levitan S. Shared decision making-pinnacle of patient-centered care. N Engl J Med 2012;366:780-1.

129.Légaré F, Witteman HO. Shared decision making: examining key elements and barriers to adoption into routine clinical practice. Health Aff (Millwood) 2013;32:276-84.

130.Emanuel EJ, Emanuel LL. Four models of the physicianpatient relationship. JAMA 1992;267:2221-6.

131. Macauley RC. Locus of decision-making. In: Ethics in Palliative Care: A Complete Guide. New York, NY: Oxford University Press, 2018:484-6.

132. Schwarze G. What We Talk about When We Talk about Surgery. John J. Conley Ethics and Philosophy Lecture presented. San Francisco, CA: Clinical Congress 2019 American College of Surgeons, 2019.

133. Quill TE, Brody H. Physician recommendations and patient 
autonomy: finding a balance between physician power and patient choice. Ann Intern Med 1996;125:763-9.

134. Schwarze ML, Campbell TC, Cunningham TV, et al. You Can't Get What You Want: Innovation for End-of-Life Communication in the Intensive Care Unit. Am J Respir Crit Care Med 2016;193:14-6.

135. Bernat JL. Ethical aspects of determining and communicating prognosis in critical care. Neurocrit Care 2004;1:107-17.

136. Berlin A, Kunac A, Mosenthal AC. Perioperative goalsetting consultations by surgical colleagues: a new model for supporting patients, families, and surgeons in shared decision making. Ann Palliat Med 2017;6:178-82.

137.De Vries R. The value of decision science for clinical ethics. AMA J Ethics 2019;21:825-30.

138. Eddy DM. Clinical decision making: from theory to practice. Anatomy of a decision. JAMA 1990;263:441-3.

139. Tunis SR. Reflections on science, judgment, and value in evidence-based decision making: a conversation with Eddy D. Health Aff (Millwood) 2007;26:w500-15.

140.Jacobsen J, Blinderman C, Cole CA, et al. "I'd Recommend ..." How to Incorporate Your Recommendation Into Shared Decision Making for Patients With Serious Illness. J Pain Symptom Manage 2018;55:1224-30.

141. Kruser JM, Nabozny MJ, Steffens NM, et al. "Best Case/Worst Case": Qualitative Evaluation of a Novel Communication Tool for Difficult in-the-Moment Surgical Decisions. J Am Geriatr Soc 2015;63:1805-11.

142. Kruser JM, Taylor LJ, Campbell TC, et al. "Best Case/Worst Case": Training Surgeons to Use a Novel Communication Tool for High-Risk Acute Surgical Problems. J Pain Symptom Manage 2017;53:711-719.e5.

143. Quill TE, Holloway R. Time-limited trials near the end of life. JAMA 2011;306:1483-4.

144. Schwarze ML, Taylor LJ. Managing Uncertainty Harnessing the Power of Scenario Planning. N Engl J Med 2017;377:206-8.

145.Ledbetter R, Marterre B. Where's the value in preoperative covenants between surgeons and patients? AMA J Ethics 2021;23:E814-22.

146. Batten JN, Kruse KE, Kraft SA, et al. What Does the Word "Treatable" Mean? Implications for Communication and Decision-Making in Critical Illness. Crit Care Med 2019;47:369-76.

147. Cook MR. Goals of Care: Understanding the Outcomes that Matter Most. Surg Clin North Am 2019;99:833-47.

148. Kopecky KE, Urbach D, Schwarze ML. Risk Calculators and Decision Aids Are Not Enough for Shared Decision
Making. JAMA Surg 2019;154:3-4.

149. Kata A, Dutt M, Sudore RL, et al. What Matters? The Valued Life Activities of Older Adults Undergoing Elective Surgery. J Am Geriatr Soc 2019;67:2305-10.

150. Epstein RM, Street RL Jr. The values and value of patientcentered care. Ann Fam Med 2011;9:100-3.

151. Kelly MP, Heath I, Howick J, et al. The importance of values in evidence-based medicine. BMC Med Ethics 2015;16:69.

152. You JJ, Allatt P, Howard M, et al. Short Graphic Values History Tool for decision making during serious illness. BMJ Support Palliat Care 2019. [Epub ahead of print]. doi: 10.1136/bmjspcare-2018-001698.

153. Taylor LJ, Johnson SK, Nabozny MJ, et al. Barriers to Goal-concordant Care for Older Patients With Acute Surgical Illness: Communication Patterns Extrinsic to Decision Aids. Ann Surg 2018;267:677-82.

154. Cooper Z, Koritsanszky LA, Cauley CE, et al. Recommendations for Best Communication Practices to Facilitate Goal-concordant Care for Seriously Ill Older Patients With Emergency Surgical Conditions. Ann Surg 2016;263:1-6.

155. Good Communication 101: Mirroring, Jargon, Hifalutin Words I Alan Alda, 2017. Available online: https://www. youtube.com/watch? $=6 \mathrm{ZzWArYi5Yc}$

156.Joseph-Williams N, Elwyn G, Edwards A. Knowledge is not power for patients: a systematic review and thematic synthesis of patient-reported barriers and facilitators to shared decision making. Patient Educ Couns 2014;94:291-309.

157.Kim SS, Kaplowitz S, Johnston MV. The effects of physician empathy on patient satisfaction and compliance. Eval Health Prof 2004;27:237-51.

158. Berlin A. Goals of Care and End of Life in the ICU. Surg Clin North Am 2017;97:1275-90.

159.Jackson VA, Jacobsen J, Greer JA, et al. The cultivation of prognostic awareness through the provision of early palliative care in the ambulatory setting: a communication guide. J Palliat Med 2013;16:894-900.

160.Paladino J, Lakin JR, Sanders JJ. Communication Strategies for Sharing Prognostic Information With Patients: Beyond Survival Statistics. JAMA 2019;322:1345-6.

161. Cook D, Rocker G. Dying with dignity in the intensive care unit. N Engl J Med 2014;370:2506-14.

162. Byock I. The 4 Things That Matter Most. Canada: Canadian Virtual Hospice; 2011. Available online: https:// www.youtube.com/watch?v=vcMmx-6RIUY 
163. Otani H, Yoshida S, Morita T, et al. Meaningful Communication Before Death, but Not Present at the Time of Death Itself, Is Associated With Better Outcomes on Measures of Depression and Complicated Grief Among Bereaved Family Members of Cancer Patients. J Pain Symptom Manage 2017;54:273-9.

164. Glare PA, Sinclair CT. Palliative medicine review: prognostication. J Palliat Med 2008;11:84-103.

165.Marsh H. Do No Harm: Stories of Life, Death, and Brain Surgery. 1st Edition. New York: Thomas Dunne Books, 2015.

166. Byock IR. The nature of suffering and the nature of opportunity at the end of life. Clin Geriatr Med 1996;12:237-52.

167. Cauley CE, Block SD, Koritsanszky LA, et al. Surgeons' Perspectives on Avoiding Nonbeneficial Treatments in Seriously Ill Older Patients with Surgical Emergencies: A Qualitative Study. J Palliat Med 2016;19:529-37.

168. Truog RD, Campbell ML, Curtis JR, et al. Recommendations for end-of-life care in the intensive care unit: a consensus statement by the American College of Critical Care Medicine. Crit Care Med 2008;36:953-63.

169. Toevs CC. Transitioning to Comfort-Focused Care at the End of Life. Surg Clin North Am 2019;99:1019-27.

170. Carlin N, Cole T, Strobel H. Guidance from the Humanities for Professional Formation. In: Cobb M, Puchlaski CM, Rumbold B, editors. Oxford Textbook of Spirituality in Healthcare. Oxford: Oxford University Press, 2012:443-9.

171. Gardner F. Training and Formation: A Case Study. In: Cobb M, Puchlaski CM, Rumbold B, editors. Oxford Textbook of Spirituality in Healthcare. Oxford: Oxford University Press; 2012:451-7.

172.Puchalski CM, Guenther M. Restoration and re-creation: spirituality in the lives of healthcare professionals. Curr Opin Support Palliat Care 2012;6:254-8.

173. Byock I. The meaning and value of death. J Palliat Med 2002;5:279-88.

174. Block SD. Perspectives on care at the close of life.

Psychological considerations, growth, and transcendence at the end of life: the art of the possible. JAMA 2001;285:2898-905.

175. Page DW. Are surgeons capable of introspection? Dunn GP, editor. Surg Clin North Am 2011;91:293-304.

176. Han K, Bohnen JD, Peponis T, et al. The Surgeon as the Second Victim? Results of the Boston Intraoperative Adverse Events Surgeons' Attitude (BISA) Study. J Am Coll Surg 2017;224:1048-56.
177. Lathrop D. Disenfranchised Grief and Physician Burnout. Ann Fam Med 2017;15:375-8.

178.Jackson VA, Sullivan AM, Gadmer NM, et al. "It was haunting...": physicians' descriptions of emotionally powerful patient deaths. Acad Med 2005;80:648-56.

179.Lebares CC, Guvva EV, Ascher NL, et al. Burnout and Stress Among US Surgery Residents: Psychological Distress and Resilience. J Am Coll Surg 2018;226:80-90.

180. Bartholomew AJ, Houk AK, Pulcrano M, et al. MetaAnalysis of Surgeon Burnout Syndrome and Specialty Differences. J Surg Educ 2018;75:1256-63.

181. Yoo PS, Tackett JJ, Maxfield MW, et al. Personal and Professional Well-Being of Surgical Residents in New England. J Am Coll Surg 2017;224:1015-9.

182. Schroeder J, Fishbach A. The 'empty vessel' physician: physicians' instrumentality makes them seem personally empty. Soc Psychol Personal Sci 2015;6:940-9.

183. Orri M, Farges O, Clavien PA, et al. Being a surgeon-the myth and the reality: a meta-synthesis of surgeons' perspectives about factors affecting their practice and wellbeing. Ann Surg 2014;260:721-8; discussion 728-9.

184. Yule S, Sacks GD, Maggard-Gibbons M. Innovative Approaches for Modifying Surgical Culture. JAMA Surg 2016;151:791-2.

185. Arora S, Sevdalis N, Nestel D, et al. The impact of stress on surgical performance: a systematic review of the literature. Surgery 2010;147:318-30, 330.e1-6.

186. Maffoni M, Argentero P, Giorgi I, et al. Healthcare professionals' moral distress in adult palliative care: a systematic review. BMJ Support Palliat Care 2019;9:245-54.

187. Moskop JC. Ethics and Health Care: An Introduction. Cambridge: Cambridge University Press, 2016.

188. Rushton CH, editor. Moral Resilience: Transforming Moral Suffering in Healthcare. 1st edition. New York, NY: Oxford University Press, 2018.

189.Dzeng E, Wachter RM. Ethics in Conflict: Moral Distress as a Root Cause of Burnout. J Gen Intern Med 2020;35:409-11.

190.Dzeng E, Colaianni A, Roland M, et al. Moral Distress Amongst American Physician Trainees Regarding Futile Treatments at the End of Life: A Qualitative Study. J Gen Intern Med 2016;31:93-9.

191. Marmon LM, Heiss K. Improving surgeon wellness: The second victim syndrome and quality of care. Semin Pediatr Surg 2015;24:315-8.

192. Siegel TR, Nagengast AK. Mitigating Burnout. Surg Clin North Am 2019;99:1029-35.

193. Nelson N, Malkoc SA, Shiv B. Emotions know best: the 
advantage of emotional versus cognitive responses to failure. J Behav Decis Mak 2018;31:40-51.

194.Heinze KE, Holtz HK, Rushton CH. Strategies for Promoting High-Quality Care and Personal Resilience in Palliative Care. AMA J Ethics 2017;19:601-7.

195. Weber E, Gray S. How Should Integrity Preservation and Professional Growth Be Balanced during Trainees' Professionalization? AMA J Ethics 2017;19:544-9.

196. Freischlag JA, Silva MM. Preventing General Surgery Residency Attrition-It Is All About the Mentoring. JAMA Surg 2017;152:272-3.

197.Pradarelli JC, Yule S, Smink DS. Performance Coaching for Practicing Surgeons Enhancing Clinical Performance, Well-Being, and Trainee Experience. J Surg Educ 2020;77:495-8.

198. Song Y, Swendiman RA, Shannon AB, et al. Can We Coach Resilience? An Evaluation of Professional Resilience Coaching as a Well-Being Initiative for Surgical Interns. J Surg Educ 2020;77:1481-9.

199. Williams RL, Lawrence E, Paul JS, et al. Implementation of a resident-led mindfulness course during the surgical clerkship. J Am Coll Surg 2019;229:S243.

200. Rushton CH, Sellers DE, Heller KS, et al. Impact of a contemplative end-of-life training program: being with dying. Palliat Support Care 2009;7:405-14.

201. Orellana-Rios CL, Radbruch L, Kern M, et al. Mindfulness and compassion-oriented practices at work reduce distress and enhance self-care of palliative care teams: a mixed-method evaluation of an "on the job" program. BMC Palliat Care 2017;17:3.

202. Raab K. Mindfulness, self-compassion, and empathy among health care professionals: a review of the literature.
J Health Care Chaplain 2014;20:95-108.

203.Epstein RM. Mindful practice. JAMA 1999;282:833-9.

204. Epstein R. Attending: Medicine, Mindfulness, and Humanity. New York: Scribner, 2017.

205.Ziegelstein RC. Creating Structured Opportunities for Social Engagement to Promote Well-Being and Avoid Burnout in Medical Students and Residents. Acad Med 2018;93:537-9.

206.Jacobs C. Reflection on the Role of the Spirit in Finding Meaning and Healing as Clinicians. J Pain Symptom Manage 2018;55:151-4.

207.Ayala EE, Omorodion AM, Nmecha D, et al. What Do Medical Students Do for Self-Care? A StudentCentered Approach to Well-Being. Teach Learn Med 2017;29:237-46.

208. Ayala EE, Winseman JS, Johnsen RD, et al. U.S. medical students who engage in self-care report less stress and higher quality of life. BMC Med Educ 2018;18:189.

209. Thirioux B, Birault F, Jaafari N. Empathy Is a Protective Factor of Burnout in Physicians: New NeuroPhenomenological Hypotheses Regarding Empathy and Sympathy in Care Relationship. Front Psychol 2016;7:763.

210. Childers J, Arnold B. The Inner Lives of Doctors: Physician Emotion in the Care of the Seriously Ill. Am J Bioeth 2019;19:29-34.

211. Cofer KD, Hollis RH, Goss L, et al. Burnout is Associated With Emotional Intelligence but not Traditional Job Performance Measurements in Surgical Residents. J Surg Educ 2018;75:1171-9.

212.Hollis RH, Theiss LM, Gullick AA, et al. Emotional intelligence in surgery is associated with resident job satisfaction. J Surg Res 2017;209:178-83.
Cite this article as: Marterre B, Kopecky K, Miller P. Primary palliative care for surgeons: a narrative review and synthesis of core competencies. Ann Palliat Med 2022;11(2):885-906. doi: 10.21037/apm-21-369 